\title{
Mosquitoes (Diptera: Culicidae) and mosquito-borne diseases in Mali, West Africa
}

\author{
Fatalmoudou Tandina ${ }^{1,2}$, Ogobara Doumbo², Alpha Seydou Yaro², Sékou F. Traoré2, Philippe Parola ${ }^{\text {* }}$
} and Vincent Robert ${ }^{3}$

\begin{abstract}
Mosquito-borne diseases cause major human diseases in almost every part of the world. In West Africa, and notably in Mali, vector control measures help reduce the impact of mosquito-borne diseases, although malaria remains a threat to both morbidity and mortality. The most recent overview article on mosquitoes in Mali was published in 1961, with a total of 88 species. Our present review focuses on mosquitoes of medical importance among which the Anopheles vectors of Plasmodium and filaria, as well as the Culex and Aedes vectors of arboviruses. It aims to provide a concise update of the literature on Culicidae, covering the ecological areas in which the species are found but also the transmitted pathogens and recent innovative tools for vector surveys. This review highlights the recent introduction of invasive mosquito species, including Aedes albopictus and Culex neavei. The comprehensive list of mosquito species currently recorded includes 106 species (28 species of the Anophelinae and 78 species of the Culicinae). There are probable gaps in our knowledge concerning mosquitoes of the subfamily Culicinae and northern half of Mali because most studies have been carried out on the genus Anopheles and have taken place in the southern part of the country. It is hoped that this review may be useful to decision makers responsible for vector control strategies and to researchers for future surveys on mosquitoes, particularly the vectors of emerging arboviruses.
\end{abstract}

Keywords: Aedes, Anopheles, Culex, Anophelinae, Culicinae, Vector

\section{Background}

Mosquito vectors can transmit several pathogens, including arboviruses, protozoans and filariae that cause infectious diseases of significant public health concern [1]. To a lesser extent, they may also transmit bacterial diseases [2]. Mosquitoes of medical importance belong to the family Culicidae and are widely distributed around the world. This large family currently encompasses 3556 valid species [3] of mosquitoes distributed within the subfamilies Culicinae and Anophelinae [4]. The mosquito vectors mainly belong to three genera, Anopheles, Aedes and Culex.

Anopheles mosquitoes have been continuously studied in Mali since 1906. The first detailed work on mosquitoes in the French Sudan (former name of Mali) has been carried out by Le Moal [5] and

\footnotetext{
* Correspondence: philippe.parola@univ-amu.fr

${ }^{1}$ Aix Marseille Univ, IRD, AP-HM, SSA, VITROME, IHU-Méditerranée Infection,

Marseille, France

Full list of author information is available at the end of the article
}

Bouffard [6]. Since then, several studies have contributed towards our understanding of this subject, but until 1950 there were only twelve known mosquito species in the country: eight Anopheles spp., one Aedes sp., two Culex spp. and one Mansonia sp. (Table 1). These data illustrate the distribution of Anopheles along the Niger River, with some information on their preimaginal development sites and adult resting places. In 1961, Hamon et al. [7] considerably improved the catalog of mosquitoes, taking into account previous works and personal observations. Their list contained 88 mosquitoes, including 20 species of the Anophelinae and 68 species of the Culicinae (Table 1). Nevertheless, many of them only existed in a few places, because the northern half of the country had not yet been surveyed. Among the Anopheles species, Hamon et al. [7] recognized Anopheles (Cellia) gambiae, An. (Cellia) funestus and An. (Cellia) nili as the main malaria vectors. 
Table 1 List of Culicidae species reported in Mali since 1908

\begin{tabular}{|c|c|c|c|c|c|}
\hline \multirow[t]{2}{*}{ Subfamily } & \multicolumn{5}{|l|}{ Species } \\
\hline & 1908 [5] & $1950[7]$ & $1961[7]$ & Recent (2000-present) & Reference ( \\
\hline \multirow[t]{29}{*}{ Anophelinae } & & & An. arabiensis & An. arabiensis & {$[72,88-90]$} \\
\hline & & & An. brohieri & & \\
\hline & & & & An. brunnipes & {$[41,89]$} \\
\hline & & & & An. coluzzii & {$[89,90]$} \\
\hline & & An. coustani & An. coustani & & \\
\hline & & & & An. domicola & {$[41,89]$} \\
\hline & & & An. flavicosta & & \\
\hline & & An. funestus & An. funestus & An. funestus & {$[41,89]$} \\
\hline & An. gambiae & An. gambiae & An. gambiae & An. gambiae & {$[72,89,90]$} \\
\hline & & & An. hancocki & & \\
\hline & & & An. leesoni & & \\
\hline & & & An. longipalpis & & \\
\hline & & & An. maculipalpis & & \\
\hline & & & & An. maliensis & {$[61]$} \\
\hline & & An. nili & An. nili & & \\
\hline & & & An. obscurus & & \\
\hline & & An. paludis & An. paludis & & \\
\hline & & An. pharoensis & An. pharoensis & & \\
\hline & & & An. pretoriensis & & \\
\hline & & & An. rhodesiensis rhodesiensis & & \\
\hline & & & An. rivulorum & & \\
\hline & & An. rufipes & An. rufipes rufipes & An. rufipes broussesi & [89] \\
\hline & & & & An. sergentii sergentii & {$[41]$} \\
\hline & & & & An. sergentii macmahoni & {$[61]$} \\
\hline & & & & An. schwetzi & {$[61]$} \\
\hline & & & & An. somalicus & {$[61]$} \\
\hline & & & An. squamosus & & \\
\hline & & & An. wellcomei wellcomei & & \\
\hline & & An. ziemanni & An. ziemanni & An. ziemanni & {$[41]$} \\
\hline \multirow[t]{14}{*}{ Culicinae } & & & Ad. africana & & \\
\hline & & & Ad. furfurea & & \\
\hline & Ae. aegypti & Ae. aegypti & Ae. aegypti & Ae. aegypti & {$[6,72,89]$} \\
\hline & & & & Ae. albopictus & {$[65]$} \\
\hline & & & Ae. africanus & & \\
\hline & & & Ae. argenteopunctatus & & \\
\hline & & & Ae. cumminsii & & \\
\hline & & & Ae. circumluteolus & & \\
\hline & & & Ae. dalzieli & & \\
\hline & & & & Ae. dialloi & {$[91]$} \\
\hline & & & Ae. fowleri & Ae. fowleri & {$[72]$} \\
\hline & & & Ae. furcifer & & \\
\hline & & & Ae. grahamii & & \\
\hline & & & Ae. haworthi & & \\
\hline
\end{tabular}


Table 1 List of Culicidae species reported in Mali since 1908 (Continued)

\begin{tabular}{|c|c|c|c|c|c|}
\hline \multirow[t]{2}{*}{ Subfamily } & \multicolumn{5}{|l|}{ Species } \\
\hline & 1908 [5] & 1950 [7] & $1961[7]$ & Recent (2000-present) & Reference (2000-present) \\
\hline & & & Ae. hirsutus & & \\
\hline & & & Ae. lineatopennis & & \\
\hline & & & Ae. luteocephalus & & \\
\hline & & & Ae. longipalpis & & \\
\hline & & & Ae. mattinglyi & & \\
\hline & & & Ae. metallicus & & \\
\hline & & & Ae. minutus & & \\
\hline & & & Ae. mucidus & & \\
\hline & & & Ae. mixtus & & \\
\hline & & & Ae. ochraceus & & \\
\hline & & & & Ae. opok & [63] \\
\hline & & & Ae. punctothoracis & & \\
\hline & & & Ae. scatophagoides & & \\
\hline & & & Ae. simpsoni (s.l.) & & \\
\hline & & & Ae. stokesi & & \\
\hline & & & & Ae. sudanensis & [64] \\
\hline & & & Ae. tarsalis & & \\
\hline & & & Ae. taylori & & \\
\hline & & & Ae. vittatus & & \\
\hline & & & Cq. aurites & & \\
\hline & & & Cq. maculipennis & & \\
\hline & & & Cq. metallica & & \\
\hline & & & Cx. albiventris & & \\
\hline & & & Cx. annulioris & & \\
\hline & & & Cx. antennatus & & \\
\hline & & & Cx. argenteopunctatus & & \\
\hline & & & Cx. bitaeniorhynchus & Cx. bitaeniorhynchus & [61] \\
\hline & & & Cx. cinereus & & \\
\hline & & & Cx. decens & & \\
\hline & & & Cx. duttoni & & \\
\hline & & & Cx. grahamii farakoensis & & \\
\hline & & & Cx. grahamii grahamii & & \\
\hline & Cx. guiarti & & Cx. guiarti & & \\
\hline & & & Cx. horridus & & \\
\hline & & & Cx. inconspicuosus & & \\
\hline & & & Cx. insignis & & \\
\hline & & & Cx. invidiosus & & \\
\hline & & & Cx. macfiei & & \\
\hline & & & Cx. nebulosus & & \\
\hline & & & & Cx. neavei & [72] \\
\hline & & & & Cx. perexiguus & [72] \\
\hline & & & Cx. perfuscus & & \\
\hline & & & CX. poicilipes & & \\
\hline
\end{tabular}


Table 1 List of Culicidae species reported in Mali since 1908 (Continued)

\begin{tabular}{|c|c|c|c|c|c|}
\hline \multirow[t]{2}{*}{ Subfamily } & \multicolumn{5}{|l|}{ Species } \\
\hline & $1908[5]$ & $1950[7]$ & $1961[7]$ & Recent (2000-present) & Reference (2000-present) \\
\hline & & & Cx. quasiguiarti & & \\
\hline & \multirow[t]{13}{*}{ Cx. quinquefasciatus } & & Cx. quinquefasciatus & Cx. quinquefasciatus & {$[43,72,88]$} \\
\hline & & & Cx. simpsoni & & \\
\hline & & & Cx. trifoliatus & & \\
\hline & & & Cx. univittatus & & \\
\hline & & & Cx. weschei & & \\
\hline & & & Cx. wigglesworthi & & \\
\hline & & & Er. dracaenae & & \\
\hline & & & Fi. uniformis & & \\
\hline & & & Mi. splendens & & \\
\hline & & & Mi. mimomyiaformis & & \\
\hline & & & Mi. plumosa & & \\
\hline & & & Mi. mediolineata & & \\
\hline & & & Ma. africana & & \\
\hline & \multirow[t]{8}{*}{ Ma. uniformis } & & Ma. uniformis & & \\
\hline & & & Tr. viridibasis & & \\
\hline & & & Tr. brevipalpis conradti & & \\
\hline & & & Ur. balfouri & & \\
\hline & & & Ur. chorleyi & & \\
\hline & & & Ur. ornata & & \\
\hline & & & Ur. mashonanensis & & \\
\hline & & & Ur. fusca & & \\
\hline
\end{tabular}

Subsequently, Touré et al. [8-10] carried out studies on the sensitivity of $A n$. gambiae (s.l.) and An. funestus to insecticides and the rates of infection with malaria parasites and filariae in the An. gambiae complex. Malaria epidemiological studies have been conducted by Doumbo et al. [11] in the Malian Sahel to fill the data gap on malaria in that region. The results showed that circulation of the malaria parasites takes place through two main vectors, Anopheles gambiae (s.s.) (chromosomal form Mopti) and Anopheles (Cel.) arabiensis in northern Mali. Anopheles gambiae (s.s.) was the only vector found in the far north of the country [12]. Several studies have been conducted on the An. gambiae complex, including An. arabiensis and chromosomal forms of An. gambiae (s.s.) targeting the differences in their human blood index (anthropophilic rate) as well as spatial and seasonal distributions [13-16].

The eco-climatic areas are classified into five facies, i.e. from north to south: the Saharan zone, the Sahelian zone, the Sudano-Sahelian zone, the Sudanian zone and finally, the Guinean zone (Fig. 1) [17]. In the different eco-climatic areas, the human malaria caused by Plasmodium spp. continues to be responsible for deaths every year in Mali. This situation is not new as the country has a long history of malaria as the leading cause of morbidity and mortality, mainly among children under five and pregnant women [18].

In order to address this public health problem, free mass distribution of long-lasting insecticide-treated mosquito nets (ITNs) has been introduced by the country's public health services, mainly for these two at-risk populations [18, 19]. Despite these control measures, malaria remains endemic with 748 deaths in 2000 and 1544 in 2015 [20, 21]. Anopheles coluzzii, An. gambiae (s.s.), An. arabiensis and An. funestus mosquitoes are the dominant vector species of the Plasmodium parasites, including $P$. falciparum, $P$. vivax, $P$. malariae, $P$. ovale wallikeri and $P$. ovale curtisi $[4,20,22]$.

Lymphatic filariasis (LF) is mosquito-borne neglected tropical disease and was considered as a public health problem [23]. Lymphatic filariasis, due to the Wuchereria brancrofti, has the same anopheline vectors as malaria [4, 24, 25]. It should be noted that since the inception of the Global Programme for the Elimination of Lymphatic Filariasis (GPELF), remarkable progress has been made in this country [23, 26]. Indeed, new cases are not reported indicating an interruption of the transmission [23, 27]. 


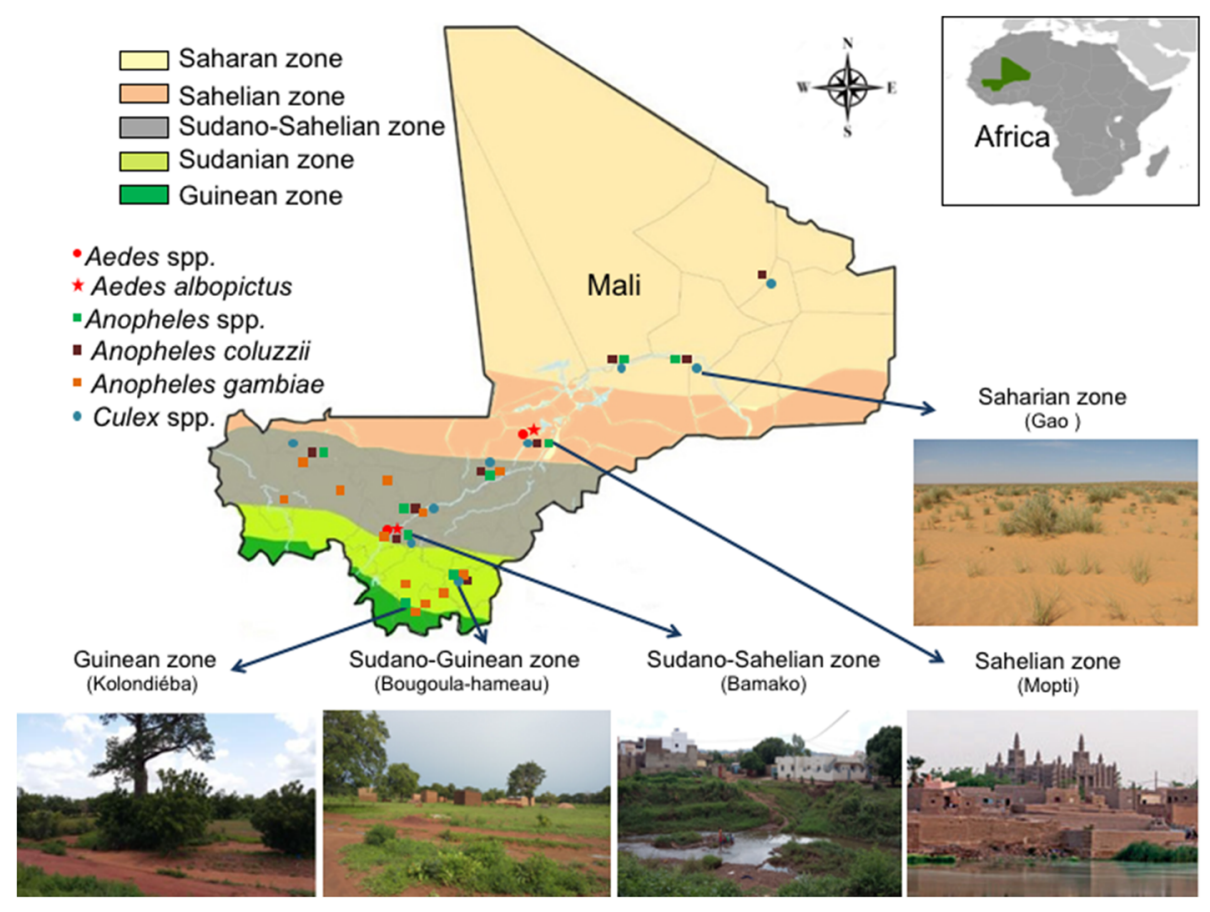

Fig. 1 Eco-climatic areas and mosquito distribution in Mali. From north to south, there are five zones including the Saharan zone, the Sahelian zone, the Sudano-Sahelian zone, the Sudanese zone and the Guinean zone. The distribution of some vector mosquitoes is reported, including: Aedes spp., Aedes albopictus, Anopheles spp., Anopheles coluzzii, Anopheles gambiae and Culex spp.

The genus Aedes contains several vector species of arboviruses, including yellow fever, dengue, chikungunya, Rift Valley fever and Zika viruses, being responsible for public health problems around almost the entire world [28-30]. Several arboviruses have been reported as being responsible for mortality and morbidity in the country [31, 32]. Three outbreaks of yellow fever have been recently reported, notably in the Sudano-Sahelian area in 1987 (Kati and Kita districts), in 2004 (Kita district), and in 2005 (Bafoulabé district). In these southern parts of the country, 58 cases and 25 deaths occurred [32, 33]. Yellow fever is a hemorrhagic fever transmitted to humans by several species of Aedes mosquitoes including Ae. (Diceromyia) furcifer and Ae. (Stegomyia) aegypti [32,33]. Rift Valley fever is a viral hemorrhagic fever affecting both humans and ruminants, and is an emerging disease which is transmitted by several mosquitoes from different genera, including Culex, Aedes and Anopheles [34-36]. Transmission of Rift Valley fever virus by Aedes may be trans-ovarian. Recently, an outbreak of Rift Valley fever was reported in western Niger, near the border with Mali $[34,37]$.

The genus Culex contains several potential vectors of pathogens such as microfilaria Wuchereria bancrofti and flaviviruses [38-40]. A number of mosquito-borne disease control measures have now been developed. The most effective are those directed against the mosquitoes, including long-lasting insecticidal nets and indoor residual spraying [20]. For mosquito control measures to be effective, it is necessary to deepen our knowledge of the resting behavior of vector species.

The purpose of this review is to provide an update of the current literature on the Malian Culicidae fauna, covering the ecological areas where they are distributed and to describe the potential pathogens transmitted. Special attention is given to mosquito vectors and the main bio-ecological characteristics of the mosquito species are detailed for the vector species only. Table 2 presents an overview of arboviruses detected in Mali. We also mention the progress made in vector mosquito control and recent innovative tools for mosquito species identification.

The complete checklist of mosquitoes currently recorded in Mali includes 106 species ( 3 of them have 2 subspecies each), grouped into the Anophelinae (28 species) and Culicinae (78 species) (Table 1, Additional file 1: Table S1).

\section{The subfamily Anophelinae: Anopheles vectors}

The subfamily Anophelinae comprises 488 officially recognized species. Of these, 60 species are important in the epidemiology of malaria, lymphatic filariasis and arboviruses [4]. In Mali, only species of the genus Anopheles are present. Twenty-eight Anopheles spp. recorded in various entomological surveys are listed in Additional file 1: Table S1 [7, 41-43].

Anopheles gambiae (s.l.), An. funestus and An. nili are the main malaria vectors [22, 44]. Anopheles gambiae populations have shown a considerable heterogeneity in 
Table 2 Mosquito-borne arboviruses in Mali

\begin{tabular}{|c|c|c|c|c|}
\hline Virus & Source of detection & Vertebrate host & Vector host & Reference \\
\hline Yellow fever & Patient serum, mosquitoes & Primates & Aedes spp. & {$[32,33,92,93$} \\
\hline Dengue & Patient serum & Primates & Aedes spp. & {$[31,93]$} \\
\hline Chikungunya & Patient serum & Primates, birds, cattle and rodents & Aedes spp.; Culex spp. & {$[31,92,93]$} \\
\hline Zika & Patient serum & Primates & Aedes spp. & {$[92,93]$} \\
\hline Rift Valley fever & Patient serum & Cows, sheep, camels, goats and other mammals & Aedes spp.; Anopheles spp.; Culex spp. & {$[34-37,93]$} \\
\hline West Nile & Patient serum & Birds, horses and other mammals & Culex spp. & {$[31,92,93]$} \\
\hline
\end{tabular}

the country [42, 45-47]. Anopheles gambiae (s.l.) includes 8 valid species, of which $A n$. arabiensis, $A n$. coluzzii and An. gambiae (s.s.) are distributed in Mali and are important malaria vectors in this country. The molecular tools used to investigate An. gambiae (s.l.) have enabled two molecular forms to be differentiated, $\mathrm{M}$ and $\mathrm{S}$. The molecular form $\mathrm{M}$ refers to the chromosomal form Mopti and was recently named An. coluzzii by Coetzee et al. [48]. The molecular form $\mathrm{S}$ retains its original name, An. gambiae (s.s.). This molecular form combines two chromosomal forms known as Savanna and Bamako. These three taxa (An. coluzzii, An. gambiae chromosomal form Savanna, and An. gambiae chromosomal form Bamako) are spread according to the ecoclimatic facies of the country [42, 45-47].

Anopheles coluzzii (Fig. 2a) is found in the northern Savanna, in the Sahel, and in the irrigated areas of the inner Niger River delta; it is the most abundant species of the An. gambiae complex in the country. Meanwhile, the Savanna chromosomal form is present in the Sudano-Sahelian and Sudano-Guinean areas, particularly in the Kayes and Sikasso regions [47]. The chromosomal form of Bamako is limited to the Sudano-Sahelian zone, particularly around Bamako and in the Sudano-Guinean zone west of Sikasso. The hybrids and recombinants between the Bamako and Coluzzii forms are limited to the Kayes region in western Mali [47].

Anopheles coluzzii and An. gambiae (s.s.) are considered highly anthropophilic and bite humans easily, mainly indoors (endophagic) but also outdoors (exophagic). The main biting activity occurs at night, and after blood-feeding, females leave (exophilic) or remain (endophilic) in these homes [49]. These species have a short larval development period and are often found in larval habitats associated with human activity. Immature stages of $A n$. coluzzii develop in permanent or subpermanent larval settings, such as the central Niger River delta and irrigated rice fields. Immature stages of $A n$. gambiae (s.s.) develop in sunny fresh water without raised vegetation $[4,50]$ and develop in temporary water such as puddles and ponds. Anopheles larval development is optimal six weeks after rice transplantation in the field [42]. Females usually take their first blood meal 24 hours after emergence and a high proportion feed again the same night after oviposition. The dispersal capacity of the females is low; they are usually found between one and three kilometers from their larval sites [1]. However, recent studies have demonstrated the potential ability of $A n$. coluzzii to migrate over long distances and aestivate [51, 52]. Thus, An. gambiae (s.s.) spreads across several biotope types which leads to the species being widely distributed. The majority of mosquitoes collected in the Sudan-Savanna ecological zone (southern Mali) consist of the sister taxa, An. gambiae (s.s.) and An. coluzzii [45]. Both species are present in the two Savanna sites, arid Savanna and humid Savanna; however, Anopheles coluzzii is predominant in the arid Savanna, and $A n$. gambiae (s.s.) is predominant in the humid Savanna [45]. Temperature and moisture play an important role in the density of mosquitoes in the ecological areas [53]. Anopheles gambiae (s.s.), An. coluzzii and An. arabiensis are the main species represented in all collections in the various ecological areas $[45,54]$.

Anopheles arabiensis is considered to be a species living in dry savannah-like environments. This species is described as anthropophilic and zoophilic; when domestic animal hosts are available, these females prefer to feed on livestock. Furthermore, the An. arabiensis species is more likely to prefer the outside environment for feeding (exophagic) and rest for digestion of blood meals (exophilic) [1, 50]. Moreover, blood-feeding usually occurs during the night. The larval habitats are similar to those of An. gambiae (s.s.), generally temporarily sunny freshwater and permanent water such as rice paddies [4, 50]. Anopheles gambiae (s.l.) and An. funestus are collected both from irrigated and non-irrigated zones [55]. In these areas, An. gambiae (s.l.) is more abundant than An. funestus [55]. However, the densities of both vectors are dynamic and are seasonally dependent. For instance, in recent decades $A n$. funestus was more abundant than An. gambiae in non-irrigated areas during the cold dry season; in contrast, in the irrigated area during the rainy season, An. gambiae (s.l.) was found to be more abundant than An. funestus [55]. In addition, these mosquito species have also been collected in the rice cultivation area of Office du Niger, located in the inner delta of the Niger River, in the Sudano-Sahelian area [56]. However, a number of recent studies conducted in non-irrigated 


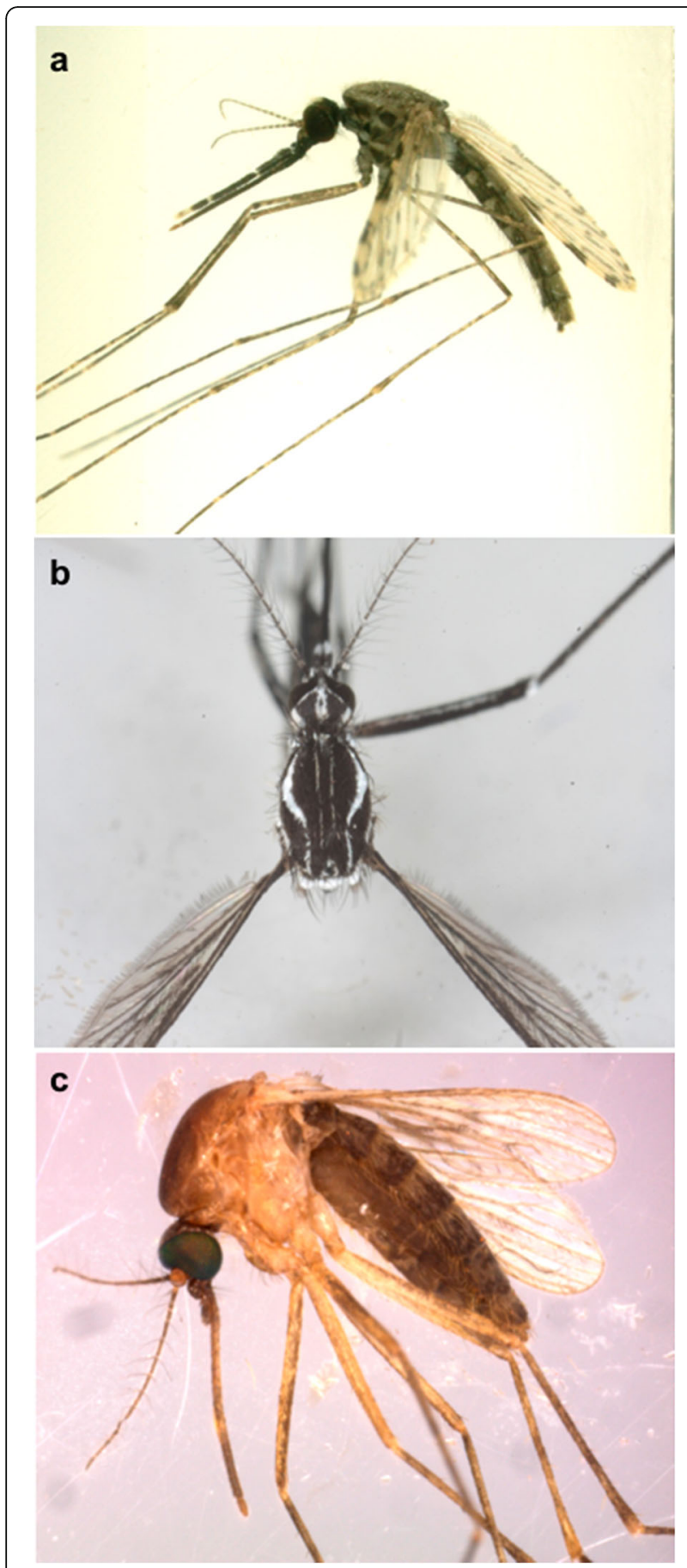

Fig. 2 Pictures of three species of mosquitoes that are potential vectors in Mali. a Anopheles coluzzii female (laboratory-reared). b Aedes aegypti female collected in Gabon. c Culex quinquefasciatus female collected in Mali

areas have revealed a significant density of An. gambiae complex, compared to An. funestus in all seasons [57].

The $A n$. funestus subgroup contains six species, including An. aruni, An. confusus, An. funestus (s.s.), An. parensis, An. vaneedeni and An. longipalpis, but only
An. funestus (s.s.) is associated with malaria transmission as a vector [3, 58, 59]. A typical larval habitat for $A n$. funestus is a permanent and semi-permanent water body with emergent vegetation. These larvae are found in marshes, large sunny ponds, lake shores and rice fields [42, 60]. Anopheles funestus is considered to be highly anthropophilic [60] as the An. gambiae complex [57]. These females usually feed indoors (endophagic) after sunset, with a peak occurring during the second half of the night. After feeding, they rest indoors (endophilic) on the upper part of the walls. In many areas, An. funestus live inside homes, making them vulnerable to residual insecticide control measures [1].

Recently An. macmahoni has been considered as being a subspecies of An. sergentii [61]. Anopheles sergentii macmahoni has never been found biting humans and has no known medical importance [50]. Anopheles sergentii sergentii is known as the oasis vector or the desert malaria vector due to its distribution within oases across the Saharan belt [50]. This species was collected in Saharan area [41]. The larval habitats are streams, seepages, canals, irrigation channels, springs, rice fields and most other shallow, unpolluted sites that contain fresh water with slow current, light emergent vegetation or algae [50]. Anopheles sergentii sergentii females are described as anthropophilic and zoophilic because they bite both humans and animals. However, this species prefer to feed indoors (endophagic) and sometimes rest for digestion of blood meal (semi-endophilic) [41].

\section{The subfamily Culicinae}

The subfamily Culicinae includes several tribes, including Aedeomyiini, Aedini, Culicini, Ficalbiini, Mansoniini, Toxorhynchitini and Uranotaeniini. A total of 78 species of the Culicinae have been recorded in various entomological surveys and are listed in Table 1 and Additional file 1: Table S1.

In this review, we present in detail only species of the genera Aedes and Culex, because the potential vectors in Mali belong to these two genera.

\section{Aedes as potential vectors in Mali}

Aedes mosquitoes are dominant vectors of most arboviruses that infect humans and animals worldwide and in West Africa [62]. The distribution of the Aedes mosquitoes and the disease they transmit depend on the ecological conditions of each area. Hamon et al. [7] reported the existence of 28 Aedes species (Table 1). Two more Aedes species, Ae. opok [63] and Ae. sudanensis [64], were then reported in Mali. Recently, Muller et al. [65] conducted an entomological survey and recorded Ae. (Stegomyia) albopictus. According to Hamon et al. [7] and Muller et al. [65], the potential vectors of arboviruses are Ae. aegypti, Ae. albopictus, Ae. (Stegomyia) africanus, Ae. 
furcifer, Ae. (Aedimorphus) fowleri, Ae. (Stegomyia) luteocephalus and Ae. (Aedimorphus) ochraceus [7, 65].

Aedes aegypti (Fig. 2b) and Ae. albopictus are the major vectors of the dengue virus (DENV). Of the four viral serotypes of DENV, three (serotypes 2, 3 and 4) are present in West Africa, particularly at the border between Burkina Faso and Mali [66, 67]. In Mali, epidemic monitoring of DENV is crucial because the Aedes vectors are present and patient serum samples were positive for this viral infection [7, 31, 65]. The chikungunya virus (CHIKV) belongs to the family Togaviridae and genus Alphavirus. The CHIKV has the same vectors as DENV and circulates in population at risk of epidemic [7, 31, 65].

Aedes aegypti is the main vector of the yellow fever virus (YFV) and is the only domestic vector of this virus in West Africa [62]. In Mali, this species has been reported in towns, villages as well as in natural wooded savannas. Their breeding water is mostly clean or has a moderate content of organic matter. Females lay their eggs in tree holes and artificial containers such as tires, flower pots, cisterns and abandoned containers, increasing the risk of urban YFV epidemics in Mali [7]. Aedes aegypti eggs are resistant to desiccation for up to one year and are able to maintain vertical transmission, allowing them to be constantly present during the dry season and to be transported passively [68]. At a favourable temperature, larvae hatch two days after laying, pupation occurs after eight days and adults emerge between nine and ten days after laying. Females bite during the day in the shade or darkness, with activity peaks in the morning and late afternoon, after feeding, they rest indoors (endophilic). They appear to prefer human blood to that of domestic animals [1].

Aedes albopictus eggs are resistant to desiccation and can survive for several months [68]. Their passive transport has allowed this species to invade several continents, although it is of Asian origin. This invasion is linked to their great ecological and physiological plasticity, which allows them to adapt to new biotopes [68]. Their longevity is around 30 days for females and 18 days for males, under favourable temperature conditions. In 2016, the first identification of Ae. albopictus in two areas (Mopti and Bamako along the Niger River) stressed the need to monitor mosquitoes [65]. These females usually bite humans and other mammalian vertebrates such as rabbits, dogs, cows, squirrels and, occasionally, avian hosts. Their opportunistic trophic preferences make them potentially capable of transferring infectious agents from animals to humans [68]. This species is exophagic during the day in umbrageous areas and endophagic at sunset and during the night [1]. Egg-laying females are attracted to containers, buckets, plastic bags, used tires and fishing boats to lay their eggs. Interestingly, all these habitats are created by humans [65].
Aedes furcifer is a sylvatic vector of YFV and DENV. This species was implicated in the yellow fever outbreak that occurred in two Sudano-Sahelian areas in the Kati and Kita districts in 1987, in Mali [33]. Their larval sites are primarily tree holes and secondary puddles on the roadside [7].

Finally, at least one species of the Ae. simpsoni complex was recorded in Mali. It remains unclear if this species is Ae. bromeliae or Ae. lilii or if both are present, but it is probably not the nominal species Ae. simpsoni (s.s.), distributed only in southern Africa $[69,70]$.

\section{Culex as potential vectors in Mali}

The genus Culex contains 769 species distributed worldwide [68, 71]. In Mali, 28 Culex species (or subspecies) belonging to four subgenera have been recorded (Additional file 1: Table S1) [7, 43, 71, 72]. Among them, $C x$. (Oculeomyia) poicilipes, Cx. (Culex) antennatus, $C x$. (Culex) quinquefasciatus and $C x$. (Culex) neavei are potential vectors of Flavivirus and lymphatic filariasis [7, 35, 43, 71-75]. Culex females lay their eggs on permanent or temporary water surfaces, their larval habitats are ponds, flooded ground, irrigated crops, river banks and tree holes [68]. Culex quinquefasciatus (Fig. 2c) is a member of the $C x$. (Culex) pipiens complex and is the most abundant species in tropical Africa. Culex quinquefasciatus is widely distributed in West Africa and is an important vector of Wuchereria bancrofti [24, 71]. Culex quinquefasciatus larvae have been reported in several types of habitat, including clear water, brackish, polluted water with organic matter and human waste, ditches, sewage, latrines and artificial containers [1]. Females bite humans and domestic animals such as poultry, dogs, cats and pigs. They are endophagic during the night and exophagic from sunset to dawn [1]. They rest indoors (endophilic) following their blood meals [68].

We recently conducted entomological surveys using classical and innovative tools in order to identify mosquitoes, such as molecular techniques and MALDI-TOF MS (see below). This allowed us to update the list of mosquito vectors in Mali by describing new mosquito species. We reported for the first time $C x$. neavei and $C x$. perexiguus [72]. Culex neavei species has been identified in three sites and is considered a potential vector of $\mathrm{WNV}$ on the border between Senegal and Mali [43, 74]. Other authors have shown that this species is a potential vector of WNV and USUV [75].

Culex poicilipes is considered a potential vector of Rift Valley Fever Virus (RVFV) in Barkedji, Senegal [35] and this mosquito species is abundant throughout Mali [7]. The larval habitats of this species include streams, flooded meadows, swamps, ponds and irrigated farmland 
along the Niger River that could increase the risk of transmission of Rift Valley fever. Furthermore, the virus is circulating on the border between Mauritania and Mali, as well as in western Niger $[37,76]$.

\section{Strategies for mosquito vector control}

National malaria control programmes, in collaboration with the WHO, have encouraged the use of mosquito nets impregnated with long-lasting insecticide and indoor residual spraying. These efforts have contributed to a decrease in malaria cases in Mali [20]. There are four classes of insecticides recommended by the WHO, namely pyrethroids, organochlorines, organophosphates and carbamates. Mosquitoes have become resistant to a number of these insecticides, posing a serious threat to the success of vector control programmes [20].

Researchers have reported An. gambiae (s.l.) resistance mecanisms to several insecticides, including dichlorodiphenyltrichloroethane (DDT), deltamethrin (PY), lambdacyhalothrin (PY), bendiocarb (CA) and fenitrothion (OP) [77]. The mutation on two target sites $(k d r$ and ace-1R) and the metabolic detoxification systems (monooxygenases and esterases) have been identified in An. coluzzii, An. gambiae (s.s.) and An. arabiensis [77].

The attractive toxic sugar bait (ATSB) plant-spraying methods against An. gambiae have reduced the density and longevity of this vector, suggesting that ATSB's plant spraying methods can be used as a new tool to control this species [78]. Recently, Lin Zhu et al. [79] confirmed the effectiveness of ATSB on malarial vectors in Africa.

Finally, the entomopathogenic fungus Beauveria bassiana treatments significantly reduced the blood-feeding of $C x$. quinquefasciatus in the field. These results show that $B$. bassiana could be a potential new mosquito control alternative [80].

Larvae control reduces the development of the vector population by using chemical toxins (larvicides), biological toxins or fish predators as biological controls [20]. Although larvicides are useful in some contexts, they are only feasible in areas where most larval sites are easily located, so they are systematically identifiable and can be fully covered by the intervention. This method often has a greater impact on transmission than adulticide methods that reduce both the density (number) of mosquitoes and their lifespan [20].

\section{Innovative methodologies for mosquito species identification}

New diseases and new vectors that colonize new territories, where they were previously absent, are continuously emerging. For example, the tiger mosquito, Ae albopictus, has been found in almost every continent of the world $[65,81]$. The mosquito-borne diseases are a major public health problem worldwide. Formal mosquito identification is essential to effectively control vectors. Morphological identification using dichotomous keys is the most widely used method for entomological surveys [49]. Currently, entomologists also use identification keys on a CD-ROM [41]. The limits of morphological identification lay in the distinction between sub-species, in particular the cryptic forms of An. gambiae (s.s.) [82]. In Mali, molecular methods were used to distinguish An. gambiae (s.l.) cryptic species and forms and certain species of the $C x$. pipiens complex, which are difficult to distinguish by their morphology [45, 47, 72, 77]. A limitation of molecular methods is their cost; the comprehensiveness of databases and the overall operating time.

Matrix-Assisted Laser Desorption Ionization-Time of Flight (MALDI-TOF MS) has revolutionized microbiology and is now routinely used. MALDI-TOF mass spectrometry has been used in medical entomology to identify arthropods [83]. This technique has been used in the laboratory for the identification of adult mosquitoes from protein extracts from the legs. Aquatic stages have also been identified, including eggs and larvae [84-86]. MALDI-TOF mass spectrometry is now used during entomological surveys. The preliminary study used field mosquitoes to update the European mosquito catalog [87].

In Mali, MALDI-TOF MS was applied on the mosquitoes and their midgut microbiota collected in the rural area of Bougoula-hameau in the Sikasso region. This technology was used to identify Malian mosquitoes from protein extracts from their legs [43]. In addition of the mosquito identification, their blood meal sources were also determined using MALDI-TOF MS. Specimens collected from three regions in the Sudan-Savanna area (around urban Bamako, the rural area of the Sikasso region and the rural area around Kati) in Mali [72]. In this country, eight mosquito species have been identified, namely An. gambiae (s.s.), An. coluzzii, An. arabiensis, Cx. quinquefasciatus, $C x$. neavei, $C x$. perexiguus, Ae. aegypti and Ae. fowleri [72]. Indeed, the mosquito blood-meal sources were correctly identified and matched with the blood of human, chicken, cow, donkey, dog and sheep. Thus, this innovative tool successfully identified Malian mosquitoes as well as their blood-meal sources and enabled the first detection of two mosquito species in Mali, $C x$. neavei and $C x$. perexiguus [72].

\section{Conclusions}

Recent collections of mosquitoes in Mali focus mainly on vector species involved in the transmission of infectious diseases that cause a public health problem. In this context, the recent publications only provide information on the ecology, distribution and associated pathogens of Anopheles, Aedes and Culex vectors. We believe that these gaps may be due to collection techniques and their relevance to public health. Indeed, a large number of vectors belonging to the family Culicidae have been identified, 
including Ae. aegypti, Ae. albopictus, An. coluzzii, An. gambiae (s.s.), An. arabiensis, An. funestus (s.s.), Cx. poicilipes, $C x$. antennatus, $C x$. quinquefasciatus and $C x$. neavei species. They are potential vectors for a number of arboviral, protozoan and filarial pathogens. Our review has contributed to updating the current literature on mosquitoes and mosquito-borne diseases in Mali. This review may be necessary for a future nationwide entomological field surveys for mosquito vector controls.

\section{Additional file}

Additional file 1: Table S1. List of mosquitoes reported in Mali, West Africa. (PDF $92 \mathrm{~kb}$ )

\section{Abbreviations}

ATSB: Attractive toxic sugar bait; CHIKV: Chikungunya virus; DENV: Dengue virus; GNTs: Glue net traps; GPELF: Global Programme for the Elimination of Lymphatic Filariasis; LF: Lymphatic filariasis; MALDI-TOF MS: Matrix-Assisted Laser Desorption Ionization Time-Of-Flight Mass Spectrometry; MRTC: Malaria Research and Training Center; RVFV: Rift Valley fever virus; USUV: Usutu virus; VITROME: Vecteurs Infections Tropicales et Mediterranéennes; WHO: World Health Organization; WNV: West Nile virus; YFV: Yellow fever virus

\section{Acknowledgements}

We thank VITROME unit, the IHU Méditerranée-Infection of Marseille, MRTC of Bamako (Mali) and the IRD of Montpellier for library resources and support during the writing of this review.

\section{Funding}

This work has been conducted with the support of the $A^{*}$ MIDEX project ( $n^{\circ}$ ANR-10-IAHU-03) funded by the Investissements d'Avenir French Government programme, managed by the French National Research Agency (ANR).

\section{Availability of data and materials}

All datasets relating to this study have been included in the article and its additional file.

\section{Authors' contributions}

FT wrote the initial draft of the manuscript, and VR, PP, OKD, SFT and ASY added their contributions and comments. All authors read and approved the final manuscript.

\section{Ethics approval and consent to participate}

Not applicable.

\section{Consent for publication}

Not applicable.

\section{Competing interests}

The authors declare that they have no competing interests.

\section{Publisher's Note}

Springer Nature remains neutral with regard to jurisdictional claims in published maps and institutional affiliations.

\section{Author details}

${ }^{1}$ Aix Marseille Univ, IRD, AP-HM, SSA, VITROME, IHU-Méditerranée Infection, Marseille, France. ${ }^{2}$ Department of Epidemiology of Parasitic Diseases, Malaria Research and Training Center, Faculty of Sciences and Techniques, University of Science, Techniques and Technologies of Bamako, Bamako, Mali. ${ }^{3}$ MIVEGEC Unit, IRD-CNRS-Univ. Montpellier, Montpellier, France.
Received: 10 February 2018 Accepted: 1 August 2018

Published online: 13 August 2018

\section{References}

1. Becker N, Petric D, Zgomba M, Boase C, Dahl C, Madon M, et al. Mosquitoes and their control. 2nd ed. Heidelberg: Springer; 2010.

2. Dieme C, Bechah Y, Socolovschi C, Audoly G, Berenger JM, Faye O, et al. Transmission potential of Rickettsia felis infection by Anopheles gambiae mosquitoes. Proc Natl Acad Sci USA. 2015;112:8088-93.

3. Harbach RE. Mosquito taxonomic inventory. 2013. http://mosquitotaxonomic-inventory info/. Accessed 15 May 2018.

4. Carnevale P, Robert V, Manguin S, Corbel V, Fontenille D, Garros C, et al. Les anophèles - biologie, transmission du Plasmodium et lutte antivectorielle. IRD ed: Marseille; 2009. 391 p.

5. Le Moal M. Etude sur les moustiques en Afrique Occidentale française (rôle pathogène-prophylaxie). Ann Hyg Méd Col. 1906;9:181-219.

6. Le BG. Stegomya fasciata au Soudan français. Bull Soc Path Exot. 1908;1:454-9.

7. Hamon J, Eyraud M, Diallo B, Dyemkouma A, Choumara HB, Sylla O. Les moustiques de la République du Mali (Diptera: Culicidae). Ann Soc Entomol Fr. 1961;130:95-129.

8. Touré YT. Sensitivity of Anopheles gambiae s.l. to insecticides in the Selingue Dam area. Parassitologia. 1984;26:311-8.

9. Touré YT, Petrarca V, Coluzzi M. Comparative estimate of the rates of infection with sporozoites and filaria in various forms of the Anopheles gambiae complex in a village in Mali. Ann Ist Super Sanita. 1986;22:215-7.

10. Touré YT. The current state of studies of malaria vectors and the antivectorial campaign in west Africa. Trans R Soc Trop Med Hyg. 1989; 83(Suppl):39-41.

11. Doumbo O, Koita O, Traoré SF, Sangaré O, Coulibaly A, Robert V, et al. Les aspects parasitologiques de l'épidemiologie du paludisme dans le Sahara Malien. Med Afr Noire. 1991;38:103-7.

12. Chauvet $G$, Benzerroug EH, Djibo A, Doumbo O, Robert $V$, Touré Y. Potentiel de transmission du paludisme dans la zone Saharo-Sahelienne de la route trans-Saharienne et des accès. Bull Soc Franc Parasitol. 1990;8:724.

13. Touré YT, Petrarca V, Traoré SF, Coulibaly A, Maiga HM, Sankaré O, et al. Ecological genetic studies in the chromosomal form Mopti of Anopheles gambiae s.str. in Mali, west Africa. Genetica. 1994;94:213-23.

14. Touré YT, Traoré SF, Sankaré O, Sow MY, Coulibaly A, Esposito F, et al. Perennial transmission of malaria by the Anopheles gambiae complex in a north Sudan Savanna area of Mali. Med Vet Entomol. 1996;10:197-9.

15. Touré YT, Dolo G, Petrarca V, Traoré SF, Bouare M, Dao A, et al. Mark-releaserecapture experiments with Anopheles gambiae s.l. in Banambani Village, Mali, to determine population size and structure. Med Vet Entomol. 1998;12: 74-83.

16. Touré YT, Petrarca V, Traoré SF, Coulibaly A, Maiga HM, Sankaré O, et al. The distribution and inversion polymorphism of chromosomally recognized taxa of the Anopheles gambiae complex in Mali. West Africa. Parassitologia. 1998; 40:477-511.

17. Global Information and Early Warning System on food and agriculture. Sahel weather and crop situation report. 2004. http://www fao org/docrep/ 006/J2517e/J2517e00.htm

18. Coulibaly D, Doumbo O, Koné D, Fall IS, Kibuchi E, Mitto B, et al. Profile épidémiologique du paludisme au Mali. Bamako: Programme National de Lutte contre le Paludisme (PNLP), Ministère de la Santé; 2015.

19. PMI. Malaria Operational Plan FY 2009. President's Malaria Initiative 2009.

20. WHO. World malaria report 2016. Geneva: World Health Organization; 2016.

21. WHO. World malaria report 2013. Geneva: World Health Organization; 2013.

22. Hay SI, Sinka ME, Okara RM, Kabaria CW, Mbithi PM, Tago CC, et al. Developing global maps of the dominant Anopheles vectors of human malaria. PLoS Med. 2010;7:e1000209.

23. WHO. Weekly epidemiological record. Geneva: World Health Organization; 2017. p. 589-608.

24. Coulibaly YI, Dembelé B, Diallo AA, Kristensen S, Konaté S, Dolo H, et al. Wuchereria bancrofti transmission pattern in southern Mali prior to and following the institution of mass drug administration. Parasit Vectors. 2013;6:247.

25. de Souza DK, Koudou B, Kelly-Hope LA, Wilson MD, Bockarie MJ, Boakye DA. Diversity and transmission competence in lymphatic filariasis vectors in West Africa, and the implications for accelerated elimination of Anophelestransmitted filariasis. Parasit Vectors. 2012;5:259.

26. Gyapong JO, Twum-Danso NA. Editorial: Global elimination of lymphatic filariasis: fact or fantasy? Trop Med Int Health. 2006;11:125-8. 
27. Coulibaly YI, Coulibaly SY, Dolo H, Konaté S, Diallo AA, Doumbia SS, et al. Dynamics of antigenemia and transmission intensity of Wuchereria bancrofti following cessation of mass drug administration in a formerly highly endemic region of Mali. Parasit Vectors. 2016;9:628.

28. Caglioti C, Lalle E, Castilletti C, Carletti F, Capobianchi MR, Bordi L. Chikungunya virus infection: an overview. New Microbiol. 2013;36: 211-27.

29. Davies FG, Koros J, Mbugua H. Rift Valley fever in Kenya: the presence of antibody to the virus in camels (Camelus dromedarius). J Hyg (Lond). 1985;94:241-4.

30. Linthicum KJ, Davies FG, Kairo A, Bailey CL. Rift Valley fever virus (family Bunyaviridae, genus Phlebovirus). Isolations from Diptera collected during an inter-epizootic period in Kenya. J Hyg (Lond). 1985;95:197-209.

31. Safronetz D, Sacko M, Sogoba N, Rosenke K, Martellaro C, Traore S, et al. Vector-borne infections, Mali. Emerg Infect Dis. 2016;22:340-2.

32. World Health Organization. Wkly Epidemiol Rec. 2008;83:449-60.

33. Cordellier R. L'épidemiologie de la fièvre jaune en Afrique de l'Ouest. Bull World Health Organ. 1991;69:73-84

34. Ba Y, Sall AA, Diallo D, Mondo M, Girault L, Dia I, et al. Re-emergence of Rift Valley fever virus in Barkedji (Senegal, West Africa) in 2002-2003: identification of new vectors and epidemiological implications. J Am Mosq Control Assoc. 2012;28:170-8.

35. Talla C, Diallo D, Dia I, Ba Y, Ndione JA, Morse AP, et al. Modelling hotspots of the two dominant Rift Valley fever vectors (Aedes vexans and Culex poicilipes) in Barkedji, Senegal. Parasit Vectors. 2016;9:111.

36. Gould E, Pettersson J, Higgs S, Charrel R, de Lamballerie X. Emerging arboviruses: why today? One Health. 2017:4:1-13.

37. Tambo E, Olalubi OA, Sacko M. Rift valley fever epidemic in Niger near border with Mali. Lancet Infect Dis. 2016;16:1319-20.

38. Anosike JC, Nwoke BE, Ajayi EG, Onwuliri CO, Okoro OU, Oku EE, et al. Lymphatic filariasis among the Ezza people of Ebonyi State, eastern Nigeria. Ann Agric Environ Med. 2005;12:181-6.

39. Komar N. West Nile virus: epidemiology and ecology in North America. Adv Virus Res. 2003;61:185-234.

40. Weaver SC, Reisen WK. Present and future arboviral threats. Antiviral Res. 2010;85:328-45.

41. Hervy J, Le Goff G, Geoffroy B, Hervé J, Manga L. Les anophèles de la région Afro-tropicale, logiciel d'identification et d'enseignement. Collection didactique. Paris: ORSTOM; 1998.

42. Klinkenberg E, Takken W, Huibers F, Touré YT. The phenology of malaria mosquitoes in irrigated rice fields in Mali. Acta Trop. 2003:85:71-82.

43. Tandina F, Almeras L, Koné AK, Doumbo OK, Raoult D, Parola P. Use of MALDI-TOF MS and culturomics to identify mosquitoes and their midgut microbiota. Parasit Vectors. 2016;9:495

44. Diuk-Wasser MA, Touré MB, Dolo G, Bagayoko M, Sogoba N, Traoré SF, et al. Vector abundance and malaria transmission in rice-growing villages in Mali. Am J Trop Med Hyg. 2005;72:725-31.

45. Coulibaly B, Koné R, Barry MS, Emerson B, Coulibaly MB, Niare O, et al. Malaria vector populations across ecological zones in Guinea Conakry and Mali. West Africa. Malar J. 2016;15:191.

46. Edillo FE, Tripet F, Touré YT, Lanzaro GC, Dolo G, Taylor CE. Water quality and immatures of the $\mathrm{M}$ and $\mathrm{S}$ forms of Anopheles gambiae s.s. and An. arabiensis in a Malian village. Malar J. 2006;5:35.

47. Sogoba N, Vounatsou P, Bagayoko MM, Doumbia S, Dolo G, Gosoniu L, et al. Spatial distribution of the chromosomal forms of Anopheles gambiae in Mali. Malar J. 2008;7:205.

48. Coetzee M, Hunt RH, Wilkerson R. della TA, Coulibaly MB, Besansky NJ. Anopheles coluzzii and Anopheles amharicus, new members of the Anopheles gambiae complex. Zootaxa. 2013;3619:246-74.

49. Gillies MT, Coetzee M. A supplement to the Anophelinae of Africa South of the Sahara. South african Institute for Medical Research: Johannesburg; 1987.

50. Sinka ME, Bangs MJ, Manguin S, Coetzee M, Mbogo CM, Hemingway J, et al. The dominant Anopheles vectors of human malaria in Africa, Europe and the Middle East: occurrence data, distribution maps and bionomic précis. Parasit Vectors. 2010;3:117.

51. Lehmann T, Weetman D, Huestis DL, Yaro AS, Kassogue Y, Diallo M, et al. Tracing the origin of the early wet-season Anopheles coluzzii in the Sahel. Evol Appl. 2017:10:704-17.

52. Dao A, Yaro AS, Diallo M, Timbine S, Huestis DL, Kassogue Y, et al. Signatures of aestivation and migration in Sahelian malaria mosquito populations. Nature. 2014;516:387-90.
53. Depinay JM, Mbogo CM, Killeen G, Knols B, Beier J, Carlson J, et al. A simulation model of African Anopheles ecology and population dynamics for the analysis of malaria transmission. Malar J. 2004;3:29.

54. Fryxell RT, Nieman CC, Fofana A, Lee Y, Traoré SF, Cornel AJ, et al. Differential Plasmodium falciparum infection of Anopheles gambiae s.s. molecular and chromosomal forms in Mali. Malar J. 2012;11:133.

55. Dolo G, Briet OJ, Dao A, Traoré SF, Bouare M, Sogoba N, et al. Malaria transmission in relation to rice cultivation in the irrigated Sahel of Mali. Acta Trop. 2004;89:147-59.

56. Sogoba N, Vounatsou P, Doumbia S, Bagayoko M, Toure MB, Sissoko IM, et al. Spatial analysis of malaria transmission parameters in the rice cultivation area of Office du Niger, Mali. Am J Trop Med Hyg. 2007;76:1009-15.

57. Yaro AS, Traoré SF, Fofana M, Fofana A, Touré YT. Study of re-infection rates in semi-immune young adults and older children living under different endemicities in Bandiagara (entomologic inoculation rates). Entomological report MRTC/FMPOS; 2002

58. Coetzee M, Fontenille D. Advances in the study of Anopheles funestus, a major vector of malaria in Africa. Insect Biochem Mol Biol. 2004;34:599-605.

59. Garros C, Harbach RE, Manguin S. Morphological assessment and molecular phylogenetics of the Funestus and Minimus groups of Anopheles (Cellia). J Med Entomol. 2005:42:522-36.

60. Gillies MT, de Meillon B. The Anophelinae of Africa South of the Sahara. The South African Institute for Medical Research: Johannesburg; 1968.

61. Gaffigan TV, Wilkerson RC, Pecor JE, Stoffer JA, Anderson T. Systematic Catalog of Culicidae. The Walter Reed Biosystematics Unit: Smithsonian Institution. www.mosquitocatalog.org. Accessed 5 Feb 2018.

62. Gardner $\mathrm{CL}$, Ryman KD. Yellow fever: a reemerging threat. Clin Lab Med. 2010;30:237-60

63. Germain M, Cordellier R, Hervé JP, Geoffroy B, Bouchite B, Ravaonjanahary C, et al. Présence en Afrique centrale et occidentale d'Aedes (Stegomyia) opok Corbet et Van Someren Diagnose différentielle de l'espèce. Cah ORSTOM Sér Ent Méd Parasitol. 1975;1:41-6.

64. Tyson WH. Notes on African Aedes, subgenus Mucidus (Diptera: Culicidae). J Ent Sot Sth Afr. 1970:33:81-8.

65. Muller GC, Tsabari O, Traoré MM, Traoré SF, Doumbia S, Kravchenko VD, et al. First record of Aedes albopictus in inland Africa along the River Niger in Bamako and Mopti, Mali. Acta Trop. 2016;162:245-7.

66. Ridde V, Agier I, Bonnet E, Carabali M, Dabire KR, Fournet F, et al. Presence of three dengue serotypes in Ouagadougou (Burkina Faso): research and public health implications. Infect Dis Poverty. 2016:5:23.

67. Vasilakis N, Cardosa J, Hanley KA, Holmes EC, Weaver SC. Fever from the forest: prospects for the continued emergence of sylvatic dengue virus and its impact on public health. Nat Rev Microbiol. 2011;9:532-41.

68. Duvallet $\mathrm{G}$, Fontenille $\mathrm{D}$, Robert $\mathrm{V}$. Entomologie médicale et vétérinaire. Marseille: IRD; 2017.

69. Huang YM. Aedes (Stegomyia) simpsoni complex in the Ethiopian region with lectotype designation for simpsoni (Theobald) (Diptera: Culicidae). Mosq Syst. 1979;11:221-34.

70. Bennett KL, Linton YM, Shija F, Kaddumukasa M, Djouaka R, Misinzo G, et al. Molecular differentiation of the African yellow fever vector Aedes bromeliae (Diptera: Culicidae) from its sympatric non-vector sister species, Aedes liliii. PLoS Negl Trop Dis. 2015;9:e0004250.

71. Harbach RE. Classification within the cosmopolitan genus Culex (Diptera: Culicidae): the foundation for molecular systematics and phylogenetic research. Acta Trop. 2011;120:1-14.

72. Tandina F, Niaré S, Laroche M, Kone AK, Diarra AZ, Ongoiba A, et al. Using MALDI-TOF MS to identify mosquitoes collected in Mali and their blood meals. Parasitology. 2018;7:1-13.

73. Coulibaly YI, Dembelé B, Diallo AA, Konaté S, Dolo H, Coulibaly SY, et al. The impact of six annual rounds of mass drug administration on Wuchereria bancrofti infections in humans and in mosquitoes in Mali. Am J Trop Med Hyg. 2015;93:356-60.

74. Fall G, Diallo M, Loucoubar C, Faye O, Sall AA. Vector competence of Culex neavei and Culex quinquefasciatus (Diptera: Culicidae) from Senegal for lineages 1, 2, Koutango and a putative new lineage of West Nile virus. Am J Trop Med Hyg. 2014;90:747-54.

75. Nikolay B, Diallo M, Faye O, Boye CS, Sall AA. Vector competence of Culex neavei (Diptera: Culicidae) for Usutu virus. Am J Trop Med Hyg. 2012;86:993-6.

76. Geering WA, Davies FG, Martin V. Préparation des plans d'intervention contre la Fièvre de la Vallée du Rift. Manuel FAO de santé Animale n¹5; 2003. 
77. Cisse MB, Keita C, Dicko A, Dengela D, Coleman J, Lucas B, et al. Characterizing the insecticide resistance of Anopheles gambiae in Mali. Malar J. 2015;14:327.

78. Muller GC, Beier JC, Traoré SF, Touré MB, Traoré MM, Bah S, et al. Successful field trial of attractive toxic sugar bait (ATSB) plant-spraying methods against malaria vectors in the Anopheles gambiae complex in Mali. West Africa. Malar J. 2010;9:210.

79. Zhu L, Marshall JM, Qualls WA, Schlein Y, McManus JW, Arheart KL, et al. Modelling optimum use of attractive toxic sugar bait stations for effective malaria vector control in Africa. Malar J. 2015;14:492.

80. Howard AF, N'guessan R, Koenraadt CJ, Asidi A, Farenhorst M, Akogbeto M, et al. The entomopathogenic fungus Beauveria bassiana reduces instantaneous blood feeding in wild multi-insecticide-resistant Culex quinquefasciatus mosquitoes in Benin. West Africa. Parasit Vectors. 2010;3:87.

81. Reis S, Cornel AJ, Melo M, Pereira H, Loiseau C. First record of Aedes albopictus (Skuse 1894) on Sao Tome island. Acta Trop. 2017;171:86-9.

82. Fanello C, Santolamazza F, della TA. Simultaneous identification of species and molecular forms of the Anopheles gambiae complex by PCR-RFLP. Med Vet Entomol. 2002;16:461-4.

83. Yssouf A, Almeras L, Raoult D, Parola P. Emerging tools for identification of arthropod vectors. Future Microbiol. 2016;11:549-66.

84. Dieme C, Yssouf A, Vega-Rua A, Berenger JM, Failloux AB, Raoult D, et al. Accurate identification of Culicidae at aquatic developmental stages by MALDI-TOF MS profiling. Parasit Vectors. 2014;7:544.

85. Schaffner F, Kaufmann C, Pfluger V, Mathis A. Rapid protein profiling facilitates surveillance of invasive mosquito species. Parasit Vectors. 2014:7:142.

86. Yssouf A, Socolovschi C, Flaudrops C, Ndiath MO, Sougoufara S, Dehecq JS, et al. Matrix-assisted laser desorption ionization - time of flight mass spectrometry: an emerging tool for the rapid identification of mosquito vectors. PLoS One. 2013;8:e72380

87. Yssouf A, Parola P, Lindstrom A, Lilja T, L'Ambert G, Bondesson U, et al. Identification of European mosquito species by MALDI-TOF MS. Parasitol Res. 2014;113:2375-8.

88. Neveu-Lemaire M. Etude des Culicidés Africains. Paris: Arch Parasitol; 1906.

89. Holstein MH. Biologie d'Anopheles gambiae. Geneva: World Health Organization; 1952.

90. Sogoba N, Vounatsou P, Bagayoko MM, Doumbia S, Dolo G, Gosoniu L, et al. The spatial distribution of Anopheles gambiae sensu stricto and An. arabiensis (Diptera: Culicidae) in Mali. Geospat Health. 2007;1:213-22.

91. Hamon J, Brengues J. Observations sur les Aedes (Aedimorphus) d'Afrique avec description de deux nouvelles espèces: Ae. lottei n. sp. et Ae. dialloi n. sp. Bull Soc Path Exot. 1965;1:101-8.

92. Brès $P$. Données récentes apportées par les enquêtes sérologiques sur la prévalence des arbovirus en Afrique, avec référence spéciale à la fièvre jaune. Bull Org Mond Santé. 1970;43:223-67.

93. Mayer SV, Tesh RB, Vasilakis N. The emergence of arthropod-borne viral diseases: A global prospective on dengue, chikungunya and Zika fevers. Acta Trop. 2017;166:155-63.

Ready to submit your research? Choose BMC and benefit from:

- fast, convenient online submission

- thorough peer review by experienced researchers in your field

- rapid publication on acceptance

- support for research data, including large and complex data types

- gold Open Access which fosters wider collaboration and increased citations

- maximum visibility for your research: over $100 \mathrm{M}$ website views per year

At BMC, research is always in progress.

Learn more biomedcentral.com/submissions 